\title{
Cytokines and Their Roles in the Pathogenesis of Systemic Lupus Erythematosus: From Basics to Recent Advances
}

\author{
Desmond Yat Hin Yap and Kar Neng Lai \\ Division of Nephrology, Department of Medicine, Queen Mary Hospital, University of Hong Kong, Pokfulam, Hong Kong \\ Correspondence should be addressed to Kar Neng Lai, knlai@hkucc.hku.hk
}

Received 12 January 2010; Accepted 2 March 2010

Academic Editor: Brian Poole

Copyright (๑) 2010 D. Y. H. Yap and K. N. Lai. This is an open access article distributed under the Creative Commons Attribution License, which permits unrestricted use, distribution, and reproduction in any medium, provided the original work is properly cited.

Systemic lupus erythematosus (SLE) is a complex auto-immune disorder which involves various facets of the immune system. In addition to autoantibody production and immune complex deposition, emerging evidences suggest that cytokines may act as key players in the immunopathogenesis of SLE. These cytokines assume a critical role in the differentiation, maturation and activation of cells and also participate in the local inflammatory processes that mediate tissue insults in SLE. Certain cytokines such as the IL-6, IL-10, IL-17, BLys, type I interferons (IFN) and tumor necrosis factor- $\alpha$ (TNF- $\alpha$ ) are closely linked to pathogenesis of SLE. The delineation of the role played by these cytokines not only fosters our understanding of this disease but also provides a sound rationale for various therapeutic approaches. In this context, this review focuses on selected cytokines which exert significant effect in the pathogenesis of SLE and their possible clinical applications.

\section{Introduction}

Systemic lupus erythematosus (SLE) is an intriguing autoimmune disease which constitutes a complex interaction between the innate and adaptive immune system. Conventional belief has cornered SLE to be primarily a disease of autoantibodies and immune complex deposition. However, mounting evidence has implied that cytokines are also key players in the pathogenesis. Cytokines are soluble factors which play a pivotal role in the differentiation, maturation, and activation of various immune cells. They are not only involved in immune dysregulation of SLE, but also in the local inflammatory response which ultimately leads to tissue injury. The knowledge of cytokines not only provides new insight into pathogenesis of SLE, but also sheds light on various clinical applications. Certain cytokines may serve as biomarkers to monitor disease activity and predict disease severity. In addition, the manipulation of these cytokines may become potential therapeutic targets for the treatment of SLE. In this context, cytokines which have significant implications in the pathogenesis of SLE will be reviewed.

\section{Interleukin 6 (IL-6)}

IL-6 is a pleiotropic cytokine synthesized predominantly by monocytes, fibroblasts, and endothelial cells, although its secretion may also be found in T- and B-lymphocytes [1]. Its production is triggered by IL-1, IL-2, and TNF- $\alpha$ but dampened by IL-4, IL-10, and IL-13. One of the most important effects of IL-6 is to induce the maturation of B lymphocytes into plasma cells and augment the immunoglobulin secretion [2, 3]. Other actions include the up-regulation of IL-2 and its receptor expression, stimulation of platelet production from megakaryocytes, differentiation of macrophage and osteoclast as well as the production of acute phase reactants [3]. IL- 6 binds to the IL- 6 receptors which belong to the type 1 cytokine receptor superfamily that consists of two subunits, namely the IL-6 R and the gp 130. The interaction between IL-6 and its receptor results in the dimerization of gp130, activation of JAK1 and subsequent tyrosine phosphorylation of gp130 [3]. The pivotal role of IL-6 in the pathogenesis of SLE had been supported by both murine and human experiments. 
2.1. Role of IL-6 in Lupus Mice Models. In MRL/lpr mice, there exists an age-related elevation of serum IL-6 levels, soluble IL6-R and aberrant expression of the IL-6 R [4, 5]. It should be highlighted that no other lymphokine studies have been shown to be capable of directly inducing the IgG anti-DNA antibodies. Exogenous administration of recombinant human IL-6 accelerated glomerulonephritis in $\mathrm{NZB} / \mathrm{W}$ mice [6]. In IL-6 deficient MRL/lpr mice, there was significant reduction of infiltrating macrophages in the kidney, a decrease in renal IgG and C3 deposition, and a diminution of $\mathrm{CD}^{+}$and $\mathrm{CD} 8^{+}$lymphocytes with the absence of IL-6 [7]. The renal parenchymal expression of adhesion molecule VCAM-1 was also found to be downregulated in MRL-Fas(lpr) IL-6-/- compared to IL-6-intact mice [7]. These data support the notion that IL-6 is a strong promoter of lupus nephritis and may be a promising new therapeutic target in the treatment of human lupus nephritis. In fact, IL- 6 blockade modulated the age-related raise in anti-ds DNA levels, retarded proteinuria and significantly improved mortality in NZB/W mice $[8,9]$. In B6.Sle1.Yaa mice, IL-6 levels were elevated and the increase was coupled with the loss of $\mathrm{CD} 19^{+} \mathrm{B}$ cells and more primitive Blymphoid progenitors in bone marrow [10]. Stimulation by IL-6 prompted these uncommitted progenitor cells to express transcription factors which inhibited lymphopoiesis and promoted myelopoiesis in SLE. Another mechanism of how IL-6 may affect the B cell survival is via the recombinationactivation gene (Rag) machinery which are crucial for the revision of rearranged immunoglobulin V (D) J genes. IL6 favors the expression of Rags and hence facilitates the rescue of autoreactive B cells from apoptosis [11]. In Jun $\mathrm{B}$ (Delaep) mice, the development of SLE phenotype was linked to increased epidermal IL- 6 secretion and intercrosses with IL-6 deficient mice could rescue the SLE phenotype [12]. These studies suggest a possible role of IL-6 in the generation of autoantibodies and the development of various clinical manifestations in animal models.

2.2. Role of IL-6 in Human SLE. In human lupus patients, accentuated IL-6 levels correlated with the disease activity and anti-DNA levels $[13,14]$. Lymphoblastoid cells isolated from lupus subjects expressed high levels of IL-6 and IL-6 antagonism resulted in reduction of anti-ds DNA in vitro [15]. In contrast to healthy subjects, B lymphocytes from lupus patients spontaneously generate heightened quantity of immunoglobulins (Ig). IL-6 blockade significantly abolished this spontaneous immunoglobulin synthesis which was restored with exogenous IL-6 administration [14]. It had been shown that B-lymphocytes from lupus patients secreted anti-ds DNA spontaneously and this autoantibody production ex vivo was predominantly caused by low density B lymphocytes [16]. It is worthwhile to note that IL-6 can facilitate these low density B cells from active lupus subjects to differentiate directly into Ig-secreting cells [16]. CD5 expression suppressed BCR signaling in SLE B cells and IL-6 down-regulated CD5 expression via DNA methylation and hence promoted the activation and expansion of autoreactive B cells in SLE patients [17]. Apart from its systemic effects, IL-6 was shown to have a particularly close link with the renal manifestation of SLE. Several studies demonstrated elevated urinary IL-6 excretion in patients with active lupus nephritis (WHO Class III/IV lupus nephritis) who also had high titers of anti-ds DNA antibodies [18, 19]. The urinary level of IL-6 in patients with active lupus nephritis was higher than that in patients with quiescent renal disease [20]. Moreover, there was enhanced in situ expression of IL-6 along the glomeruli and tubules in lupus nephritis kidneys [21]. Apart from the kidneys, neuropsychiatric manifestation was associated with an excessive IL-6 levels in the cerebrospinal fluid of lupus patients [22]. These findings of raised IL-6 in local tissues have suggested the pathogenetic role of IL-6 in mediating local inflammation and tissue insults. IL-6 and its receptors may be useful biomarkers to monitor disease activity and treatment response. IL-6 release from PBMC was associated with disease activity and treatment response in lupus nephritis patients [23]. Other studies have also revealed an increased expression of IL6 agonistic receptor gp130 on peripheral lymphocytes in SLE patients and its level correlated with the disease activity [24]. The success of IL-6 antagonism in murine models has prompted research into the therapeutic application of IL-6 in human lupus. Tocilizumab (Anti-IL6 R antagonist) when used in mild to moderate lupus patient has demonstrated preliminary success and good tolerability in phase I trials [25].

\section{Interleukin 10 (IL-10)}

IL-10 is a cytokine produced mainly by monocytes and lymphocytes. It impedes the activation of antigen presenting cells (APC), down-regulates the expression of costimulatory molecules and, thereby, blunts $\mathrm{T}$ cell activation and TNF- $\alpha$ secretion [26]. IL-10 boosts B cell proliferation and immunoglobulin class switching resulting in enhanced antibody secretion with the capacity to enter extravascular compartments and promote inflammation in SLE. Several stimuli, including anti-ds DNA antibodies and immune complexes when bound to Fc $\gamma$ RII, are potent triggers of IL$10[27,28]$. Prominent staining of IL-10 in intra-renal cells was detected in kidneys of lupus patients [29], although the data suggested that the IFN $\gamma /$ IL-10 ratio is of more clinical relevance. Elevated IFN $\gamma / \mathrm{IL}-10$ ratio was observed in active class IV lupus nephritis, while class V nephritis may behave oppositely in this regard [29]. Apparently, the increased IL-10 was of pathogenic bearing in NZB/W mice where the effects of IL-10 were largely opposite to those of TNF- $\alpha$ [30]. In fact, anti-IL10 therapy led to increased TNF- $\alpha$ and its beneficial effects were abrogated when TNF- $\alpha$ was blocked [30]. On the other hand, IL-10 appeared to play a role in the regulatory $\mathrm{T}$ cell commitment and action [31], which might be beneficial in SLE. The observed down-regulation of $\mathrm{T}$ cell activation in peripheral blood mononuclear cells from SLE patients was consistent with such effects [32]. In animal models of lupus nephritis, anti-IL 10 blockade offered some benefits in limiting renal damage [33]. Preliminary data have shown that anti-IL-10 monoclonal antibody improved cutaneous lesions, joint symptoms, and SLEDAI in lupus patients [34]. 


\section{Interleukin 17 (IL-17)}

IL-17 is a type I transmembrane protein isolated initially from a rodent $\mathrm{CD}^{+} \mathrm{T}$ cell cDNA library [35]. It is a potent pro-inflammatory cytokine produced by activated $\mathrm{T}$ lymphocytes, with the "Th17 cells" being the most vibrant producer. These Th17 cells are in fact a subset of CD4 ${ }^{+}$ T lymphocytes named after its hallmark cytokine IL-17. Th17 cells are regarded as a distinct $\mathrm{T}$ helper cell subset because they originate from naïve $\mathrm{T}$ cells and only exhibit a characteristic cytokine release profile when appropriately primed by exclusive transcription factors. There are a total of six family members (IL-17 A to F) and five receptors (IL-17R A to E) in the IL-17 family [36]. IL-17 has great potency to recruit monocytes and neutrophils, facilitate $\mathrm{T}$ cell infiltration, and up-regulate adhesion molecule expressions [37, 38]. Several important cytokines including IL6, IL-21, and IL-23 are in intimate association with IL-17. The combination of IL- 6 and transforming growth factor (TGF) $\beta$ was shown to induce the differentiation of murine naïve $\mathrm{T}$ cells into Th17 cells $[39,40]$. Conversely, IL-6 deficient mice demonstrated defective Th17 differentiation [39]. These observations implied that the presence of an inflammatory signal is required to transform the naïve $\mathrm{T}$ cells to become pro-inflammatory. IL-21 is another factor which exerts a strong influence for Th-17 differentiation. Unlike IL-6, IL-21 is produced by the Th17 cells as well as the T-follicular helper cells but not by antigen presenting cells and, hence, being postulated to act as an auto-amplifier of Th17 response [40]. Moreover, it is important to note the effect of IL-23 on a pathogenic Th17 response in naïve wildtype mice upon $\mathrm{T}$ cell adoptive transfer [41]. In addition, IL-23 enhances IL-17 production by memory T cells [42]. Taken together, these findings suggest the presence of a novel $\mathrm{T}$ helper functional axis (IL-23/IL-17 axis) which may be important in the pathogenesis of autoimmune disorders. Although naïve $\mathrm{CD}^{+}{ }^{+} \mathrm{T}$ cells can differentiate into Th1, Th2, or Th17 effector subsets, the cytokine milieu characteristic of SLE patients (IL-2 poor but IL-6 and IL-21 rich) favors Th17 expansion. Th17 cells can also serve as an independent $\mathrm{T}$ helper effector cell subset promoting inflammation through cytokine secretion. The signature cytokines secreted by the Th17 cells include IL-17A, IL-17F, IL-21, and IL-22 [43]. This array of cytokines can stimulate B lymphocytes, and set off local inflammation and tissue injury leading to the pathogenesis of SLE. Evidences supporting the role of IL-17 in SLE pathogenesis are found in both animal and human lupus.

4.1. Role of IL-17 in Lupus Mice Models. In MRL/lpr mice, enhanced IL-17 mediated tissue injury was observed after ischemic reperfusion of the gut [44]. In IL-12R deficient BXD2 mice, there was diminished splenic germinal centre formation as well as lower anti-DNA and antihistone antibodies levels [45]. Furthermore, splenocytes from $\mathrm{SNF}_{1}$ mice secreted higher level of IL-17 than non-autoimmune B6 mice [46]. $\mathrm{CD}^{+} \mathrm{CD}^{-} \mathrm{CD}^{-} \mathrm{T}$ cells from MRL/lpr mice produced copious IL-17 and the expression of IL-17 and IL-23 receptors in the lymphocytes from these mice increased as the disease progressed [47]. These lymphoid cells from MRL/lpr mice, after treatment with IL-23 in vitro and transferred to non-autoimmune species, can induce nephritis [47]. These data indicate that an aberrantly active IL-23/IL-17 axis is responsible for the development of nephritis in lupus-prone mice.

4.2. Role of $I L-17$ in Human SLE. In human subjects, SLE patients have raised serum levels of IL-17 and IL-23 and the plasma level of IL-17 correlates with disease activity [48]. Recent data have suggested that a significant portion of IL-17 in SLE patients is contributed by the TCR- $\alpha \beta^{+} \mathrm{CD} 4^{-} \mathrm{CD} 8^{-}$ T lymphocytes [49]. These CR- $\alpha \beta^{+} \mathrm{CD} 4^{-} \mathrm{CD} 8^{-} \mathrm{T}$ cells and Th17 cells are also found in renal biopsies from lupus nephritis patients, supporting their pathogenic role in renal lupus [49].

\section{B-Lymphocytes Stimulators (BLys)}

B lymphocyte stimulator (BLys) is a member of the tumor necrosis factor ligand family. Being a type-II transmembrane protein, it is cleaved at the cell surface by furin protease that results in the release of a soluble, biologically active molecule [50]. Expression of BLys is highly confined to myeloid lineage cells (e.g., monocytes, macrophages, dendritic cells and activated neutrophils) and its release is upregulated by interferon- $\gamma$ and IL-10 [50]. BLys couples intensely to B lymphocytes and is a vital factor for B lymphocyte proliferation and immunoglobulin secretion as suggested by recent data [51]. In BLys-deficient mice, there is significant shrinkage in numbers of mature B cells, reduced baseline serum immunoglobulin levels and impaired immunoglobulin response to $\mathrm{T}$ cell dependent and independent antigens [52]. Three types of BLys receptor are found, namely, BAFFR, BCMA, and TACI receptors. BLys can bind to these three receptors on $\mathrm{B}$ cells, whereas a proliferation-inducing ligand (APRIL) can only engage to TACI and BCMA [53]. Among these three receptors, the BAFFR receptor is the most important one mediating most of the BLys effects. Mice deficient in BCMA and TACI receptors exhibit no discernible phenotypic or functional abnormalities $[52,54]$. In contrast, $\mathrm{A} / \mathrm{WySnJ}$ mice (which bear a mutated baffr gene) display a reduction in mature B cell numbers and antibody level reminiscent of BLys-deficient mice [55]. BLys-triggered intracellular events are complex mainly mediating through the interaction of BLys receptors and several TNF receptor associated factors (TRAFs). Docking of BLys with its receptors activates phospholipase C- $\gamma 2$ [56] and subsequently the NF- $\kappa$ B pathways [57]. This results in the inhibition of $B$ cell apoptosis and hence prolonged B lymphocyte survival.

5.1. Role of BLys in Lupus Mice Models. In murine models, there are several distinct observations which suggest the contribution of BLys to the pathogenesis of SLE. In BLys transgenic mice (BLys-Tg mice), overproduction of BLys not only leads to polyclonal hypergammaglobulinemia but also elevated titres of multiple autoantibodies (including anti-ds DNA), circulating immune complexes and renal immunoglobulin deposition [58]. These mice develop 


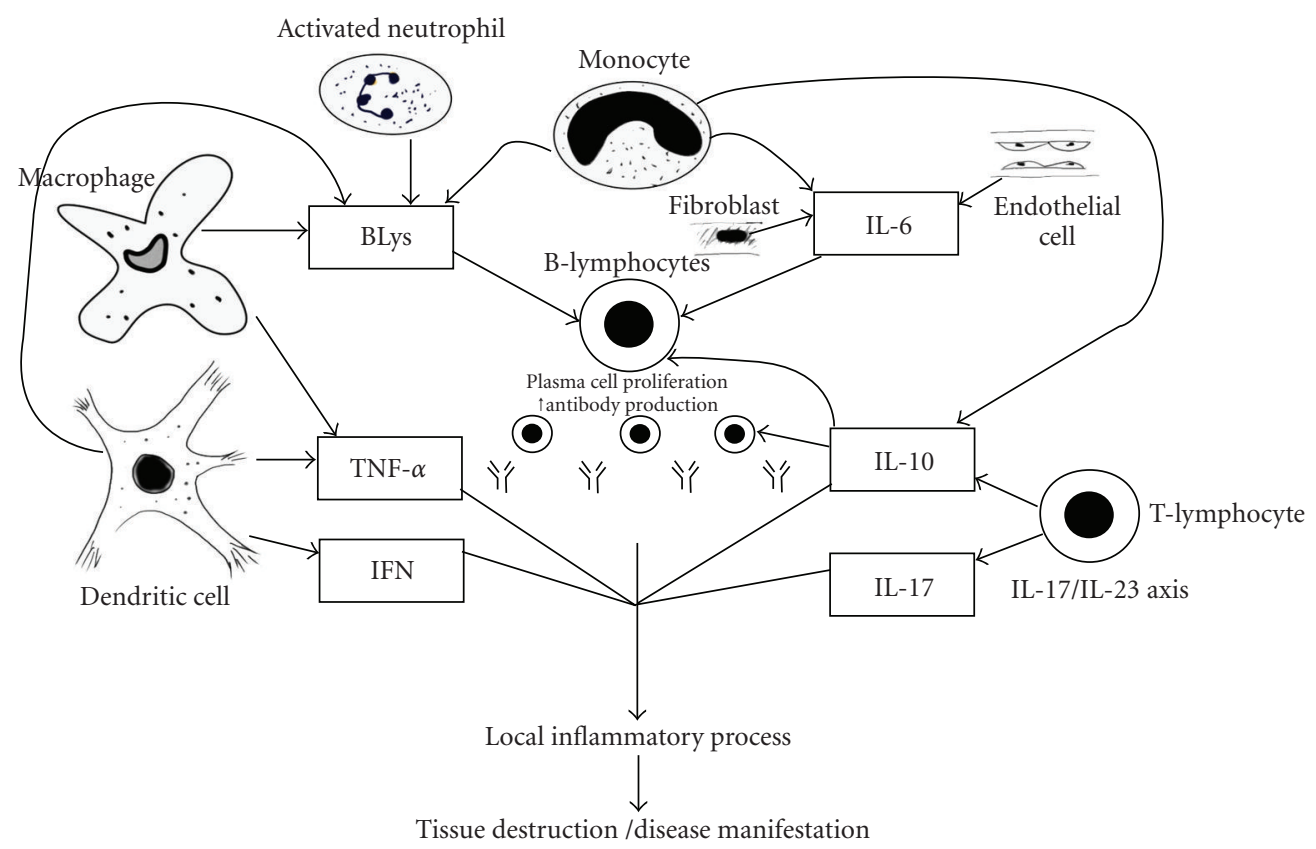

FIGURE 1: Schematic diagram to show the complex interaction between various immune cells and cytokines which lead to the pathogenesis of SLE.

autoimmune disorders similar to SLE and Sjogren syndrome [58]. In SLE-prone mice such as the (NZB/W) F1 mice and MRL-lpr/lpr mice, raised levels of BLys are detected at the onset of disease [59]. Treatment of NZB/WF1 mice with soluble TACI-Ig fusion protein prevented the development of proteinuria and prolonged the survival of the animals [59]. These findings highlight the involvement of BLys and its receptors in the development of SLE and indirectly suggest TACI-Ig as a promising treatment for human autoimmune disease. Furthermore, mice treated with exogenous BLys showed increased numbers of antichromatin B cells and augmented production of anti-ds DNA antibodies [60]. Deletion of either BLys or BR3 severely impaired B cell development beyond the transitional developmental stages [52, 55, 59, 61]. T-cell-deficient BAFF transgenic (Tg) mice developed SLE similar to T-cell-sufficient BAFF Tg mice, and these features were associated with innate activation of $B$ cells and release of pro-inflammatory autoantibodies. These data suggest that a dysregulated innate activation of B cells alone can drive disease independently of the T cells [62].

5.2. Role of BLys in Human SLE. Circulating level of BLys was raised in human lupus patients and the level correlated with the anti-ds DNA level [63]. In a survey which measured the serum BLys level and disease activities, healthy controls uniformly displayed a normal serum BLys level over time, whereas escalated BLys level was observed in SLE patients (persistent elevation in 25\% and intermittent elevation in another $25 \%$ of patients) [64]. Although the aforementioned observations make BLys a promising therapeutic target, data regarding BLys-targeted therapy are not as encouraging as expected in lupus patients. In a phase I trial of Belimumab (a fully humanized monoclonal antibody (IgG1) that binds to soluble BLys and hence inhibits its binding to TACI, BCMA, and BAFFR), there was no significant improvement in disease activity despite a reduction in the $\mathrm{CD}_{20} 0^{+} \mathrm{B}$ cells [65]. Trial of atacicept (a fusion protein against the TACI receptor) showed a trend toward clinical improvement in moderate SLE [66], yet phase II trial of this drug in lupus nephritis was suspended due to high risk of severe infections.

\section{Type I Interferons (Type I IFN)}

Interferons (IFN) are proteins with the capacity to suppress viral replications: the types I IFNs are regarded the most important ones in human lupus. Viral DNA and RNA are classical triggers of type I IFN and the signals are mediated via the Toll-like receptors (TLR) or the retinoic acidinducible gene I (RIG-I) like receptors [67]. Double-stranded RNA stimulates IFN release via TLR3 while single stranded RNA induces IFN via TLR7/8 and the cytosine-phosphateguanine $(\mathrm{CpG})$ rich DNA via TLR9 [68]. Type I IFNs are produced by all leucocytes with plasmacytoid dendritic cells (PDC) as the most active secretor in response to TLR7 or TLR9 activation [69]. Several mechanisms of how IFNs may contribute to the pathogenesis of SLE have been proposed. Immune complexes generated from autoantibodies and autoantigens lead to dendritic cell activation and hence enhanced antigen presentation and increased IFN secretion [70]. IFNs can increase the expression of autoantigen such as Ro52 [71] and also the release of autoantigens by translocation of Ro52 to the nucleus with subsequent induction of apoptosis [72]. Other actions include the promotion of dendritic cell maturation and upregulation of cell surface molecules (MHC Class I and II, costimulatory molecules) 
TABLE 1: Important cytokines in SLE: the major secreting cells and possible clinical applications.

\begin{tabular}{|c|c|c|}
\hline Cytokines & Major secreting cells & Possible Clinical applications \\
\hline \multirow{3}{*}{ IL-6 } & Monocytes & \multirow{3}{*}{$\begin{array}{l}\text { (i) Tocilizumab (Anti-IL6R Ab) showed good efficacy and tolerability in phase } 1 \text { trial } \\
\text { for mild to moderate lupus [25] }\end{array}$} \\
\hline & Fibroblasts & \\
\hline & Endothelial cells & \\
\hline \multirow{2}{*}{ IL-10 } & Monocytes & \multirow{2}{*}{$\begin{array}{l}\text { (ii) Anti-IL10 monoclonal antibody improve cutaneous lesions, joint symptoms and } \\
\text { SLEDAI in lupus patients [34] }\end{array}$} \\
\hline & Lymphocytes & \\
\hline IL-17 & $\begin{array}{l}\text { Lymphocytes } \\
\text { (Th-17 subset) }\end{array}$ & (iii) Still under investigation \\
\hline \multirow{4}{*}{ BLys } & Monocytes & (iv) Belimumab (monoclonal Ab against soluble BLys) showed reduction in $\mathrm{CD} 20^{+} \mathrm{B}$ \\
\hline & Macrophages & cells but no significant improvement in disease activity [65] \\
\hline & Dendritic cells & \multirow{2}{*}{$\begin{array}{l}\text { (v) Atacicept (fusion protein against TACI receptor) showed clinical improvement for } \\
\text { moderate lupus but phase II trial suspended due to high infective risk }\end{array}$} \\
\hline & Activated neutrophils & \\
\hline $\begin{array}{l}\text { Type } 1 \text { Interferon } \\
\text { (IFN) }\end{array}$ & $\begin{array}{l}\text { Plasmacytoid dendritic } \\
\text { cells (PDC) }\end{array}$ & $\begin{array}{l}\text { (vi) IFN regulated chemokines used in monitoring of disease activity and organ } \\
\text { damage [90,91] } \\
\text { (vii) Anti-IFN monoclonal antibody showed improvement in disease activity in phase } \\
\text { I trial [92] }\end{array}$ \\
\hline \multirow{3}{*}{ TNF-alpha } & Macrophages & \multirow{2}{*}{$\begin{array}{l}\text { (viii) Infliximab (Anti-TNF } \alpha \text { ) improved joint symptoms and proteinuria in lupus } \\
\text { patients with moderate activity [103] }\end{array}$} \\
\hline & Dendritic cells & \\
\hline & & $\begin{array}{l}\text { (ix) Infliximab (Anti-TNF } \alpha \text { ) resulted in sustained remission in Class IV lupus } \\
\text { nephritis patients who failed to achieve remission with steroid/MMF/cyclosporine } \\
{[104]}\end{array}$ \\
\hline
\end{tabular}

[73]. These effects orchestrate the development of Th1 response. In addition, type I IFNs also enhance antibody production and class switching, decrease the selectivity of B cells for CpG-rich DNA, and permit stimulation by even non-CpG DNA $[74,75]$. Elevation of type I IFN in lupus patients was one of the first described cytokine abnormalities in autoimmune diseases. The association of IFN levels and disease activity, anti-ds DNA levels, and clinical manifestations supports the role of IFN in SLE pathogenesis [76]. Although PDC population is lower in the peripheral blood of lupus patients, they are found in the dermal lesions and are responsible for the continuous IFN release [77]. PDC can also accumulate in active lupus nephritis and the migration of these cells to the glomeruli is thought to be influenced by IL-18 [78]. Findings from experimental lupus model suggested that IFN drive the lupus nephritis and end organ damage [79]. Autoantibodies with the ability to form very potent interferogenic immune complexes together with RNA-containing autoantigens were detected in the cerebrospinal fluid of patients with cerebral lupus [80]. Gene expression profiling showed that SLE patients expressed IFN inducible genes in PBMC and the expression correlated with disease activities [71]. These findings demonstrate that raised IFN levels are capable of inducing alterations in gene expression in active lupus patients and support the notion that IFNs play an important pathogenic role in SLE. In the contrary, deficiency of the IFN $\alpha / \beta$ receptor resulted in attenuation of autoantibody production and amelioration of disease in NZB/W mice [81]. This again provides indirect evidence that IFNs exert a significant impact on SLE.
Moreover, patients receiving anti-IFN therapy for other disease may develop autoantibodies and SLE-like syndrome [82]. The causal role of IFN in SLE is further supported by genetic studies. Transcription factor IRF5 was the first identified gene directly involved in IFN production and was associated with increased risk of lupus [83]. Lupus patients with a risk haplotype of IRF5 had higher serum IFN activity when compared to patients lacking this risk genotype and the effect was most prominent in patients with autoantibodies against either RNA-binding proteins or double-stranded DNA [84]. Another example is the signal transducer and activator of transcription 4 (STAT4) which interacts with the cytoplasmic part of the IFNAR and variants of STAT4 have been shown to be strongly associated with lupus [85]. A link between the IFN response and SLE had also been established for patients with polymorphism of Jak TYK2 [86]. Clinical applications of the IFN include the use as a biomarker as well as a therapeutic target. Healthy first degree relatives of lupus patients have increased serum IFN activity [87] and the levels are more pronounced in younger individuals [88]. A combination of risk alleles in the type I signaling pathway (e.g., STAT4 and IRF5) may imply an additive risk of disease [89]. It can be inferred that the use of genetic mapping may help predicting the development and severity of disease in the future. IFN regulated chemokines may also be employed to monitor disease activity and organ damage $[90,91]$. A phase I clinic trial of anti-IFN monoclonal antibodies showed a dose-dependent inhibition of type I IFN-inducible genes in both the peripheral blood and skin biopsies in parallel with reduction in disease activity [92]. 


\section{Tumor Necrosis Factor- $\alpha$ (TNF- $\alpha)$}

Tumor necrosis factor-alpha (TNF- $\alpha$ ) is expressed as a trimer on cell surface and in soluble form after the activation of macrophages and dendritic cells. The significance of TNF- $\alpha$ in the pathogenesis of SLE remains controversial since it has been depicted as both protective and detrimental in different murine models.

7.1. Role of TNFa in Lupus Mice Models. Previous findings in NZB/W mice showed diminished production of TNF- $\alpha$ [93]. In NZB/W mice, TNF- $\alpha$ deficiency is an important trigger for lupus-like autoimmunity. While TNF- $\alpha$ deficient $\mathrm{NZB} / \mathrm{W}$ mice develop severe disease manifestations, TNF- $\alpha$ competent NZB/W mice only show modest lupus activity [94]. In contrast, TNF- $\alpha$ concentration was high in both sera and renal tissue of MRL/lpr lupus mice and the levels of TNF- $\alpha$ correlated with the severity of kidney disease [95]. Moreover, even in NZB/W mice, renal expression of TNF$\alpha$ is elevated in conjunction with kidney inflammation [96]. In MRL/lpr mice, anti-TNF $\alpha$ therapy offered improvement of joint and lung manifestations in these animal models $[97,98]$.

7.2. Role of TNF- $\alpha$ in Human SLE. There is substantial evidence to show that TNF- $\alpha$ may play a similar proinflammatory role in human SLE. Serum levels of TNF- $\alpha$ in active SLE patients closely correlated with disease activity [99] and abundant TNF- $\alpha$ expression was demonstrated in lupus nephritis kidneys [23]. Nevertheless, conflicting results were observed in patients with other autoimmune diseases receiving anti-TNF- $\alpha$ therapy $[100,101]$. These patients developed antinuclear factors, anti-ds DNA and anticardiolipin antibodies as well as a lupus-like syndrome. Yet these symptoms and autoantibodies resolved following discontinuation of TNF- $\alpha$ blocking therapy. Given the findings of elevated serum TNF- $\alpha$ in active SLE and overexpression of TNF- $\alpha$ in active lupus nephritis [23, 102], TNF- $\alpha$ antagonism still appears to be an attractive option for the treatment of active lupus disease. However, evidence for therapeutic efficacy of TNF- $\alpha$ blockade in SLE is still limited $[103,104]$ and larger prospective studies are needed to evaluate their effectiveness and side effects profile.

\section{Concluding Remarks}

This review has discussed an array of information on a possible pathogenic link between the various cytokines and SLE (Figure 1). There are still many facets of inflammatory cascades elicited by these cytokines to be elucidated. A more in-depth understanding of these cytokines may be of clinical significance in the context of devising biomarkers or therapeutic agents (Table 1). Most of the recent trials have addressed the use of cytokinetargeted agents in the induction phase of severe disease manifestation or in refractory cases. These new therapies may offer an advantage to achieve rapid disease control and to minimize the corticosteroid usage. However, the role of these anticytokine treatments in the maintenance phase still remains undefined. One must also appreciate that interactions between the cytokine milieus are complex and the attenuation of one cytokine may have potentiated more profound effects than expected. The longterm use of these cytokines as a therapeutic target may appear attractive, yet one must be alerted to the possible complications such as infection and malignancy.

\section{Acknowledgment}

K. N. Lai is supported by the L\&T Charitable Foundation and the House of INDOCAFE.

\section{References}

[1] T. Hiran, "IL-6 and its receptor," International Reviews of Immunology, vol. 16, pp. 249-284, 1998.

[2] A. Schimpl and E. Wecker, "Replacement of T-cell function by a T-cell product," Nature: New Biology, vol. 237, no. 70, pp. 15-17, 1972.

[3] E. Tackey, P. E. Lipsky, and G. G. Illei, "Rationale for interleukin-6 blockade in systemic lupus erythematosus," Lupus, vol. 13, no. 5, pp. 339-343, 2004.

[4] H. Suzuki, K. Yasukawa, T. Saito, et al., "Serum soluble interleukin-6 receptor in MRL/lpr mice is elevated with age and mediates the interleukin-6 signal," European Journal of Immunology, vol. 23, no. 5, pp. 1078-1082, 1993.

[5] B. Tang, T. Matsuda, S. Akira, et al., "Age-associated increase in interleukin 6 in MRL/lpr mice," International Immunology, vol. 3, no. 3, pp. 273-278, 1991.

[6] B. Ryffel, B. D. Car, H. Gunn, D. Roman, P. Hiestand, and M. J. Mihatsch, "Interleukin-6 exacerbates glomerulonephritis in (NZBxNZW)F1 mice," American Journal of Pathology, vol. 144, no. 5, pp. 927-937, 1994.

[7] H. Cash, M. Relle, J. Menke, et al., "Interleukin 6 (IL-6) deficiency delays lupus nephritis in MRL-Fas ${ }^{l p r}$ mice: the IL-6 pathway as a new therapeutic target in treatment of autoimmune kidney disease in systemic lupus erythematosus," Journal of Rheumatology, vol. 37, no. 1, pp. 60-70, 2010.

[8] B. K. Finck, B. Chan, and D. Wofsy, "Interleukin 6 promotes murine lupus in NZB/NZW F1 mice," Journal of Clinical Investigation, vol. 94, no. 2, pp. 585-591, 1994.

[9] M. Mihara, N. Takagi, Y. Takeda, and Y. Ohsugi, "IL6 receptor blockage inhibits the onset of autoimmune kidney disease in NZB/WF1 mice," Clinical and Experimental Immunology, vol. 112, no. 3, pp. 397-402, 1998.

[10] K. Maeda, A. Malykhin, B. N. Teague-Weber, X.-H. Sun, A. D. Farris, and K. M. Coggeshall, "Interleukin-6 aborts lymphopoiesis and elevates production of myeloid cells in systemic lupus erythematosus-prone B6.Sle1.Yaa animals," Blood, vol. 113, no. 19, pp. 4534-4540, 2009.

[11] H. Tagoh, H. Kishi, and A. Muraguchi, "Molecular cloning and characterization of a novel stromal cell-derived cDNA encoding a protein that facilitates gene activation of recombination activating gene (RAG)-1 in human lymphoid progenitors," Biochemical and Biophysical Research Communications, vol. 221, no. 3, pp. 744-749, 1996.

[12] P. Pflegerl, P. Vesely, B. Hantusch, et al., "Epidermal loss of JunB leads to a SLE phenotype due to hyper IL-6 signaling," Proceedings of the National Academy of Sciences of the United States of America, vol. 106, no. 48, pp. 20423-20428, 2010.

[13] G. Grondal, I. Gunnarsson, J. Ronnelid, et al., "Cytokine production, serum levels and disease activity in systemic 
lupus erythematosus," Clinical and Experimental Rheumatology, vol. 18, pp. 565-570, 2000.

[14] M. Linker-Israeli, R. J. Deans, D. J. Wallace, J. Prehn, T. OzeriChen, and J. R. Klinenberg, "Elevated levels of endogenous IL-6 in systemic lupus erythematosus: a putative role in pathogenesis," Journal of Immunology, vol. 147, no. 1, pp. 117-123, 1991.

[15] D. J. Klashman, R. A. Martin, O. Martinez-Maza, and R. H. Stevens, "In vitro regulation of B cell differentiation by interleukin-6 and soluble CD23 in systemic lupus erythematosus B cell subpopulations and antigen-induced normal B cells," Arthritis \& Rheumatism, vol. 34, no. 3, pp. 276-286, 1991.

[16] A. Kitani, M. Hara, T. Hirose, et al., "Autostimulatory effects of IL-6 on excessive B cell differentiation in patients with systemic lupus erythematosus: analysis of IL-6 production and IL-6R expression," Clinical and Experimental Immunology, vol. 88, no. 1, pp. 75-83, 1992.

[17] A. Kitani, M. Hara, T. Hirose, et al., "Heterogeneity of B cell responsiveness to interleukin 4, interleukin 6 and low molecular weight B cell growth factor in discrete stages of B cell activation in patients with systemic lupus erythematosus," Clinical and Experimental Immunology, vol. 77, no. 1, pp. 31-36, 1989.

[18] S. Garaud, C. Le Dantec, S. Jousse-Joulin, et al., "IL-6 modulates CD5 expression in B cells from patients with lupus by regulating DNA methylation," Journal of Immunology, vol. 182, no. 9, pp. 5623-5632, 2009.

[19] M. Iwano, K. Dohi, E. Hirata, et al., "Urinary levels of IL-6 in patients with active lupus nephritis," Clinical Nephrology, vol. 40, no. 1, pp. 16-21, 1993.

[20] C.-Y. Tsai, T.-H. Wu, C.-L. Yu, J.-Y. Lu, and Y.-Y. Tsai, "Increased excretions of $\beta_{2}$-microglobulin, IL-6, and IL-8 and decreased excretion of Tamm-Horsfall glycoprotein in urine of patients with active lupus nephritis," Nephron, vol. 85, no. 3, pp. 207-214, 2000.

[21] R. Herrera-Esparza, O. Barbosa-Cisneros, R. VillalobosHurtado, and E. Avalos-Diaz, "Renal expression of IL-6 and TNF- $\alpha$ genes in lupus nephritis," Lupus, vol. 7, no. 3, pp. 154$158,1998$.

[22] S. Hirohata, Y. Kanai, A. Mitsuo, Y. Tokano, and H. Hashimoto, "Accuracy of cerebrospinal fluid IL-6 testing for diagnosis of lupus psychosis. A multicenter retrospective study," Clinical Rheumatology, vol. 28, no. 11, pp. 1319-1323, 2009.

[23] P. Esposito, M. M. Balletta, A. Procino, L. Postiglione, and B. Memoli, "Interleukin-6 release from peripheral mononuclear cells is associated to disease activity and treatment response in patients with lupus nephritis," Lupus, vol. 18, no. 14, pp. 1329-1330, 2009.

[24] M. De La Torre, J. M. Urra, and J. Blanco, "Raised expression of cytokine receptor gp130 subunit on peripheral lymphocytes of patients with active lupus. A useful tool for monitoring the disease activity?" Lupus, vol. 18, no. 3, pp. 216-222, 2009.

[25] G. Illei, C. Yarboro, Y. Shirota, et al., "Tocilizumab (humanized anti-IL6 Receptor Monoclonal Antibody) in patients with systemic lupus erythematosus (SLE): safety, tolerability and preliminary efficacy," Arthritis \& Rheumatism, vol. 54, no. 12, supplement, p. 4043, 2006.

[26] L. Llorente, W. Zou, Y. Levy, et al., "Role of interleukin 10 in the B lymphocyte hyperactivity and autoantibody production of human systemic lupus erythematosus," Journal of Experimental Medicine, vol. 181, no. 3, pp. 839-844, 1995.
[27] J. Ronnelid, A. Tejde, L. Mathsson, K. Nilsson-Ekdahl, and B. Nilsson, "Immune complexes from SLE sera induce IL10 production from normal peripheral blood mononuclear cells by an Fc $\gamma$ RII dependent mechanismml: implications for a possible vicious cycle maintaining B cell hyperactivity in SLE," Annals of the Rheumatic Diseases, vol. 62, no. 1, pp. 3742, 2003.

[28] K. H. Sun, C. L. Yu, S. J. Tang, and G. H. Sun, "Monoclonal anti-double-stranded DNA autoantibody stimulates the expression and release of IL1- $\beta$, IL-6, IL-8, IL-10 and TNF- $\alpha$ from normal human mononuclear cells involving in the lupus pathogenesis," Immunology, vol. 99, pp. 352-360, 2000.

[29] W.-S. Uhm, K. Na, G.-W. Song, et al., "Cytokine balance in kidney tissue from lupus nephritis patients," Rheumatology, vol. 42, no. 8, pp. 935-938, 2003.

[30] H. Ishida, T. Muchamuel, S. Sakaguchi, S. Andrade, S. Menon, and M. Howard, "Continuous administration of anti-interleukin 10 antibodies delays onset of autoimmunity in NZB/W F1 mice," Journal of Experimental Medicine, vol. 179, no. 1, pp. 305-310, 1994.

[31] E. M. Shevach, "CD4 ${ }^{+} \mathrm{CD} 25^{+}$suppressor T cells: more questions than answers," Nature Reviews Immunology, vol. 2, no. 6, pp. 389-400, 2002.

[32] B. R. Lauwerys, N. Garot, J.-C. Renauld, and F. A. Houssiau, "Interleukin-10 blockade corrects impaired in vitro cellular immune responses of systemic lupus erythematosus patients," Arthritis \& Rheumatism, vol. 43, no. 9, pp. 19761981, 2000.

[33] C. T. Ravirajan, Y. Wang, L. A. Matis, et al., "Effect of neutralizing antibodies to IL-10 and C5 on the renal damage caused by a pathogenic human anti-ds DNA antibody," Rheumatology, vol. 43, no. 4, pp. 442-447, 2004.

[34] L. Llorente, Y. Richaud-Patin, C García-Padilla, et al., "Clinical and biologic effects of anti-interleukin-10 monoclonal antibody administration in systemic Lupus erythematosus," Arthritis \& Rheumatism, vol. 43, no. 8, pp. 1790-1800, 2000.

[35] E. Rouvier, M.-F. Luciani, M.-G. Mattei, F. Denizot, and P. Golstein, "CTLA-8, cloned from an activated $\mathrm{T}$ cell, bearing AU-rich messenger RNA instability sequences, and homologous to a herpesvirus Saimiri gene," Journal of Immunology, vol. 150, no. 12, pp. 5445-5456, 1993.

[36] C. T. Weaver, R. D. Hatton, P. R. Mangan, and L. E. Harrington, "IL-17 family cytokines and the expanding diversity of effector T cell lineages," Annual Review of Immunology, vol. 25, pp. 821-852, 2007.

[37] S. Agarwal, R. Misra, and A. Aggarwal, "Interleukin 17 levels are increased in juvenile idiopathic arthritis synovial fluid and induce synovial fibroblasts to produce proinflammatory cytokines and matrix metalloproteinases," Journal of Rheumatology, vol. 35, no. 3, pp. 515-519, 2008.

[38] C. Albanesi, A. Cavani, and G. Girolomoni, "IL-17 is produced by nickel-specific $\mathrm{T}$ lymphocytes and regulates ICAM-1 expression and chemokine production in human keratinocytes: synergistic or antagonist effects with IFN- $\gamma$ and TNF- $\alpha$," Journal of Immunology, vol. 162, no. 1, pp. 494502, 1999.

[39] E. Bettelli, Y. Carrier, W. Gao, et al., "Reciprocal developmental pathways for the generation of pathogenic effector TH17 and regulatory T cells," Nature, vol. 441, no. 7090, pp. 235238, 2006.

[40] P. R. Mangan, L. E. Harrington, D. B. O'Quinn, et al., "Transforming growth factor- $\beta$ induces development of the $\mathrm{T}_{\mathrm{H}} 17$ lineage,” Nature, vol. 441, no. 7090, pp. 231-234, 2006. 
[41] C. L. Langrish, Y. Chen, W. M. Blumenschein, et al., "IL-23 drives a pathogenic $\mathrm{T}$ cell population that induces autoimmune inflammation," Journal of Experimental Medicine, vol. 201, no. 2, pp. 233-240, 2005.

[42] S. Aggarwal, N. Ghilardi, M.-H. Xie, F. J. De Sauvage, and A. L. Gurney, "Interleukin-23 promotes a distinct CD4 $\mathrm{T}$ cell activation state characterized by the production of interleukin-17," Journal of Biological Chemistry, vol. 278, no. 3, pp. 1910-1914, 2003.

[43] A. Nalbandian, J. C. Crispin, and G. C. Tsokos, "Interleukin17 and systemic lupus erythematosus: current concepts," Clinical and Experimental Immunology, vol. 157, no. 2, pp. 209-215, 2009.

[44] C. Edgerton, J. C. Crispin, C. M. Moratz, et al., "IL-17 producing $\mathrm{CD}^{+}{ }^{+} \mathrm{T}$ cells mediate accelerated ischemia/reperfusion-induced injury in autoimmunityprone mice," Clinical Immunology, vol. 130, no. 3, pp. 313-321, 2009.

[45] H.-C. Hsu, P. A. Yang, J. Wang, et al., "Interleukin 17producing $\mathrm{T}$ helper cells and interleukin 17 orchestrate autoreactive germinal center development in autoimmune BXD2 mice," Nature Immunology, vol. 9, no. 2, pp. 166-175, 2008.

[46] H.-K. Kang, M. Liu, and S. K. Datta, "Low-dose peptide tolerance therapy of lupus generates plasmacytoid dendritic cells that cause expansion of autoantigen-specific regulatory T cells and contraction of inflammatory Th17 cells," Journal of Immunology, vol. 178, no. 12, pp. 7849-7858, 2007.

[47] Z. Zhang, V. C. Kyttaris, and G. C. Tsokos, "The role of IL23/IL-17 axis in lupus nephritis," Journal of immunology, vol. 183, no. 5, pp. 3160-3169, 2009.

[48] C. K. Wong, L. C. W. Lit, L. S. Tam, E. K. M. Li, P. T. Y. Wong, and C. W. K. Lam, "Hyperproduction of IL-23 and IL-17 in patients with systemic lupus erythematosus: implications for Th17-mediated inflammation in auto-immunity," Clinical Immunology, vol. 127, no. 3, pp. 385-393, 2008.

[49] J. C. Crispin, M. Oukka, G. Bayliss, et al., "Expanded double negative $\mathrm{T}$ cells in patients with systemic lupus erythematosus produce IL-17 and infiltrate the kidneys," Journal of Immunology, vol. 181, no. 12, pp. 8761-8766, 2008.

[50] B. Nardelli, O. Belvedere, V. Roschke, et al., "Synthesis and release of B-lymphocyte stimulator from myeloid cells," Blood, vol. 97, no. 1, pp. 198-204, 2001.

[51] P. A. Moore, O. Belvedere, A. Orr, et al., "BLyS: member of the tumor necrosis factor family and B lymphocyte stimulator," Science, vol. 285, no. 5425, pp. 260-263, 1999.

[52] B. Schiemann, J. L. Gommerman, K. Vora, et al., "An essential role for BAFF in the normal development of B cells through a BCMA-independent pathway," Science, vol. 293, no. 5537, pp. 2111-2114, 2001.

[53] C. Bossen, T. G. Cachero, A. Tardivel, et al., "TACI, unlike BAFF-R, is solely activated by oligomeric BAFF and APRIL to support survival of activated B cells and plasmablasts," Blood, vol. 111, no. 3, pp. 1004-1012, 2008.

[54] S. Xu and K.-P. Lam, "B-cell maturation protein, which binds the tumor necrosis factor family members BAFF and APRIL, is dispensable for humoral immune responses," Molecular and Cellular Biology, vol. 21, no. 12, pp. 4067-4074, 2001.

[55] M. Yan, J. R. Brady, B. Chan, et al., "Identification of a novel receptor for B lymphocyte stimulator that is mutated in a mouse strain with severe B cell deficiency," Current Biology, vol. 11, no. 19, pp. 1547-1552, 2001.
[56] M. Hikida, S. Johmura, A. Hashimoto, M. Takezaki, and T. Kurosaki, "Coupling between B cell receptor and phospholipase C- $\gamma_{2}$ is essential for mature B cell development," Journal of Experimental Medicine, vol. 198, no. 4, pp. 581-589, 2003.

[57] E. N. Hatada, R. K. G. Do, A. Orlofsky, et al., "NF- $\kappa$ B1 p50 is required for BLyS attenuation of apoptosis but dispensable for processing of NF- $\kappa$ B2 p100 to p52 in quiescent mature B cells," Journal of Immunology, vol. 171, no. 2, pp. 761-768, 2003.

[58] F. Mackay, S. A. Woodcock, P. Lawton, et al., "Mice transgenic for BAFF develop lymphocytic disorders along with autoimmune manifestations," Journal of Experimental Medicine, vol. 190, no. 11, pp. 1697-1710, 1999.

[59] J. A. Gross, J. Johnston, S. Mudri, et al., "TACI and BCMA are receptors for a TNF homologue implicated in B-cell autoimmune disease," Nature, vol. 404, no. 6781, pp. 995999, 2000.

[60] B. D. Hondowicz, S. T. Alexander, W. J. Quinn, et al., "The role of BLyS/BLyS receptors in anti-chromatin B cell regulation," International Immunology, vol. 19, no. 4, pp. 465-475, 2007.

[61] J. S. Thompson, P. Schneider, S. L. Kalled, et al., "BAFF binds to the tumor necrosis factor receptor-like molecule B cell maturation antigen and is important for maintaining the peripheral B cell population," Journal of Experimental Medicine, vol. 192, no. 1, pp. 129-135, 2000.

[62] J. Groom and F. Mackay, "B cells flying solo," Immunology and Cell Biology, vol. 86, no. 1, pp. 40-46, 2008.

[63] G. S. Cheema, V. Roschke, D. M. Hilbert, and W. Stohl, "Elevated serum B lymphocyte stimulator levels in patients with systemic immune-based rheumatic diseases," Arthritis \& Rheumatism, vol. 44, no. 6, pp. 1313-1319, 2001.

[64] W. Stohl, S. Metyas, S.-M. Tan, et al., "B lymphocyte stimulator overexpression in patients with systemic lupus erythematosus: longitudinal observations," Arthritis \& Rheumatism, vol. 48, no. 12, pp. 3475-3486, 2003.

[65] R. Furie, W. Stohl, E. M. Ginzler, et al., "Biologic activity and safety of belimumab, a neutralizing anti-B-lymphocyte stimulator (BLyS) monoclonal antibody: a phase I trial in patients with systemic lupus erythematosus," Arthritis Research and Therapy, vol. 10, no. 5, article R109, 2008.

[66] M. Dall'Era, E. Chakravarty, D. Wallace, et al., "Reduced B lymphocyte and immunoglobulin levels after atacicept treatment in patients with systemic lupus erythematosus: results of a multicenter, phase Ib, double-blind, placebocontrolled, dose-escalating trial," Arthritis \& Rheumatism, vol. 56, no. 12, pp. 4142-4150, 2007.

[67] O. Takeuchi and S. Akira, "Innate immunity to virus infection," Immunological Reviews, vol. 227, no. 1, pp. 75-86, 2009.

[68] B. Beutler, "The Toll-like receptors: analysis by forward genetic methods," Immunogenetics, vol. 57, no. 6, pp. 385392, 2005.

[69] P. Fitzgerald-Bocarsly, J. Dai, and S. Singh, "Plasmacytoid dendritic cells and type I IFN: 50 years of convergent history," Cytokine and Growth Factor Reviews, vol. 19, no. 1, pp. 3-19, 2008.

[70] T. Lovgren, M.-L. Eloranta, U. Bave, et al., "Induction of interferon- $\alpha$ production in plasmacytoid dendritic cells by immune complexes containing nucleic acid released by necrotic or late apoptotic cells and lupus IgG," Arthritis \& Rheumatism, vol. 50, no. 6, pp. 1861-1872, 2004. 
[71] E. C. Baechler, F. M. Batliwalla, G. Karypis, et al., "Interferoninducible gene expression signature in peripheral blood cells of patients with severe lupus," Proceedings of the National Academy of Sciences of the United States of America, vol. 100, no. 5, pp. 2610-2615, 2003.

[72] L. Strandberg, A. Ambrosi, A. Espinosa, et al., "Interferon- $\alpha$ induces up-regulation and nuclear translocation of the Ro52 autoantigen as detected by a panel of novel Ro52-specific monoclonal antibodies," Journal of Clinical Immunology, vol. 28, no. 3, pp. 220-231, 2008.

[73] R. Baccala, K. Hoebe, D. H. Kono, B. Beutler, and A. N. Theofilopoulos, "TLR-dependent and TLR-independent pathways of type I interferon induction in systemic autoimmunity," Nature Medicine, vol. 13, no. 5, pp. 543-551, 2007.

[74] A. Le Bon, C. Thompson, E. Kamphuis, et al., "Cutting edge: enhancement of antibody responses through direct stimulation of B and T cells by type I IFN," Journal of Immunology, vol. 176, no. 4, pp. 2074-2078, 2006.

[75] M. B. Uccellini, L. Busconi, N. M. Green, et al., "Autoreactive B cells discriminate CpG-rich and CpG-poor DNA and this response is modulated by IFN- $\alpha$," Journal of Immunolog $y$, vol. 181, no. 9, pp. 5875-5884, 2008.

[76] A. A. Bengtsson, G. Sturfelt, L. Truedsson, et al., "Activation of type I interferon system in systemic lupus erythematosus correlates with disease activity but not with antiretroviral antibodies," Lupus, vol. 9, no. 9, pp. 664-671, 2000.

[77] S. Blomberg, M. L. Eloranta, B. Cederblad, et al., "Presence of cutaneous interferon- $\alpha$ producing cells in patients with systemic lupus erythematosus," Lupus, vol. 10, no. 7, pp. 484490, 2001.

[78] M. Tucci, C. Quatraro, L. Lombardi, C. Pellegrino, F. Dammacco, and F. Silvestris, "Glomerular accumulation of plasmacytoid dendritic cells in active lupus nephritis: role of interleukin-18," Arthritis \& Rheumatism, vol. 58, no. 1, pp. 251-262, 2008.

[79] A.-M. Fairhurst, A. Mathian, J. E. Connolly, et al., "Systemic IFN- $\alpha$ drives kidney nephritis in B6.Sle123 mice," European Journal of Immunology, vol. 38, no. 7, pp. 1948-1960, 2008.

[80] D. M. Santer, T. Yoshio, S. Minota, et al., "Potent induction of IFN- $\alpha$ and chemokines by autoantibodies in the cerebrospinal fluid of patients with neuropsychiatric lupus," Journal of Immunology, vol. 182, no. 2, pp. 1192-1201, 2009.

[81] M.-L. Santiago-Raber, R. Baccala, K. M. Haraldsson, et al., "Type-I interferon receptor deficiency reduces lupus-like disease in NZB mice," Journal of Experimental Medicine, vol. 197, no. 6, pp. 777-788, 2003.

[82] Y. Ioannou and D. A. Isenberg, "Current evidence for the induction of autoimmune rheumatic manifestations by cytokine therapy," Arthritis \& Rheumatism, vol. 43, no. 7, pp. 1431-1442, 2000.

[83] S. Sigurdsson, G. Nordmark, H. H. H. Goring, et al., "Polymorphisms in the tyrosine kinase 2 and interferon regulatory factor 5 genes are associated with systemic lupus erythematosus," American Journal of Human Genetics, vol. 76, no. 3, pp. 528-537, 2005.

[84] T. B. Niewold, J. A. Kelly, M. H. Flesch, L. R. Espinoza, J. B. Harley, and M. K. Crow, "Association of the IRF5 risk haplotype with high serum interferon- $\alpha$ activity in systemic lupus erythematosus patients," Arthritis \& Rheumatism, vol. 58, no. 8, pp. 2481-2487, 2008.

[85] E. F. Remmers, R. M. Plenge, A. T. Lee, et al., "STAT4 and the risk of rheumatoid arthritis and systemic lupus erythematosus," The New England Journal of Medicine, vol. 357, no. 10, pp. 977-986, 2007.

[86] D. S. C. Graham, M. Akil, and T. J. Vyse, "Association of polymorphisms across the tyrosine kinase gene, TYK2 in UK SLE families," Rheumatology, vol. 46, no. 6, pp. 927-930, 2007.

[87] T. B. Niewold, J. Hua, T. J. A. Lehman, J. B. Harley, and M. K. Crow, "High serum IFN- $\alpha$ activity is a heritable risk factor for systemic lupus erythematosus," Genes and Immunity, vol. 8, no. 6, pp. 492-502, 2007.

[88] T. B. Niewold, J. E. Adler, S. B. Glenn, T. J. A. Lehman, J. B. Harley, and M. K. Crow, "Age- and sex-related patterns of serum interferon- $\alpha$ activity in lupus families," Arthritis \& Rheumatism, vol. 58, no. 7, pp. 2113-2119, 2008.

[89] S. Sigurdsson, G. Nordmark, S. Garnier, et al., "A risk haplotype of STAT4 for systemic lupus erythematosus is overexpressed, correlates with anti-dsDNA and shows additive effects with two risk alleles of IRF5," Human Molecular Genetics, vol. 17, no. 18, pp. 2868-2876, 2008.

[90] J. W. Bauer, E. C. Baechler, M. Petri, et al., "Elevated serum levels of interferon-regulated chemokines are biomarkers for active human systemic lupus erythematosus," PLoS Medicine, vol. 3, no. 12, article e491, pp. 2274-2284, 2006.

[91] Q. Fu, X. Chen, H. Cui, et al., "Association of elevated transcript levels of interferon-inducible chemokines with disease activity and organ damage in systemic lupus erythematosus patients," Arthritis Research and Therapy, vol. 10, no. 5, article R112, 2008.

[92] D. J. Wallace, M. Petri, N. Olsen, et al., "MEDI-545, an anti-interferon $\alpha$ monoclonal antibody, shows evidence of clinical activity in systemic lupus erythematosus," Arthritis \& Rheumatism, vol. 56, pp. S562-S563, 2007.

[93] C. O. Jacob and H. O. McDevitt, "Tumor necrosis factor- $\alpha$ in murine autoimmune lupus nephritis," Nature, vol. 331, pp. 356-358, 1988.

[94] D. Kontoyiannis and G. Kollias, "Accelerated autoimmunity and lupus nephritis in NZB mice with an engineered heterozygous deficiency in tumor necrosis factor," European Journal of Immunology, vol. 30, no. 7, pp. 2038-2047, 2000.

[95] H. Yokoyama, B. Kreft, and V. R. Kelley, "Biphasic increase in circulating and renal TNF- $\alpha$ in MRL-lpr mice with differing regulatory mechanisms," Kidney International, vol. 47, no. 1, pp. 122-130, 1995.

[96] D. C. Brennan, M. A. Yui, R. P. Wuthrich, and V. E. Kelley, "Tumor necrosis factor and IL-1 in New Zealand black/white mice. Enhanced gene expression and acceleration of renal injury," Journal of Immunology, vol. 143, no. 11, pp. 34703475, 1989.

[97] C. K. Edwards, T. Zhou, J. Zhang, et al., "Inhibition of superantigen-induced proinflammatory cytokine production and inflammatory arthritis in MRL-Ipr/Ipr mice by a transcriptional inhibitor of TNF- $\alpha$," Journal of Immunology, vol. 157, no. 4, pp. 1758-1772, 1996.

[98] Y. Deguchi and S. Kishimoto, "Tumour necrosis factor/cachectin plays a key role in autoimmune pulmonary inflammation in lupus-prone mice," Clinical and Experimental Immunology, vol. 85, no. 3, pp. 392-395, 1991.

[99] C. Gabay, N. Cakir, F. Moral, et al., "Circulating levels of tumor necrosis factor soluble receptors in systemic lupus erythematosus are significantly higher than in other rheumatic diseases and correlate with disease activity," Journal of Rheumatology, vol. 24, no. 2, pp. 303-308, 1997. 
[100] A. K. Mohan, E. T. Edwards, T. R. Cote, J. N. Siegel, and M. M. Braun, "Drug-induced systemic lupus erythematosus and TNF- $\alpha$ blockers," The Lancet, vol. 360, no. 9333, p. 646, 2002.

[101] N. Shakoor, M. Michalska, C. A. Harris, and J. A. Block, "Drug-induced systemic lupus erythematosus associated with etanercept therapy," The Lancet, vol. 359, no. 9306, pp. 579-580, 2002.

[102] T. J. Neale, B. M. Ruger, H. Macaulay, et al., "Tumor necrosis factor- $\alpha$ is expressed by glomerular visceral epithelial cells in human membranous nephropathy," American Journal of Pathology, vol. 146, no. 6, pp. 1444-1454, 1995.

[103] M. Aringer, W. B. Graninger, G. Steiner, and J. S. Smolen, "Safety and efficacy of tumor necrosis factor $\alpha$ blockade in systemic lupus erythematosus: an open-label study," Arthritis \& Rheumatism, vol. 50, no. 10, pp. 3161-3169, 2004.

[104] S. J. Hayat, S. S. Uppal, M. R. Narayanan Nampoory, K. V. Johny, R. Gupta, and M. Al-Oun, "Safety and efficacy of infliximab in a patient with active WHO class IV lupus nephritis," Clinical Rheumatology, vol. 26, no. 6, pp. 973-975, 2007. 


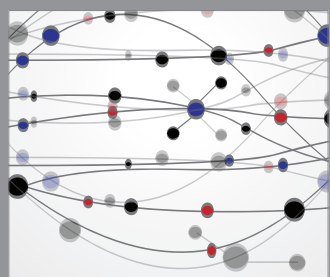

The Scientific World Journal
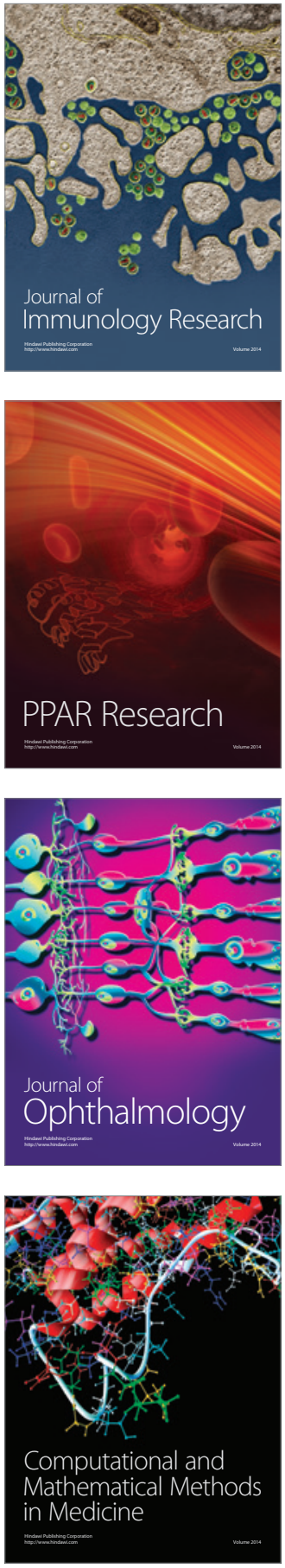

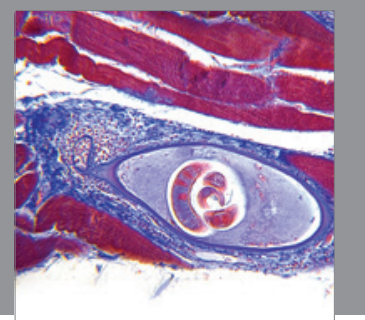

Gastroenterology

Research and Practice
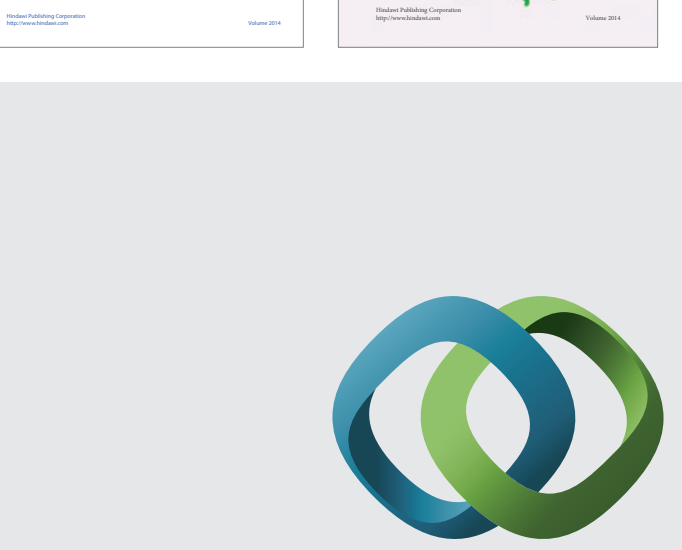

\section{Hindawi}

Submit your manuscripts at

http://www.hindawi.com
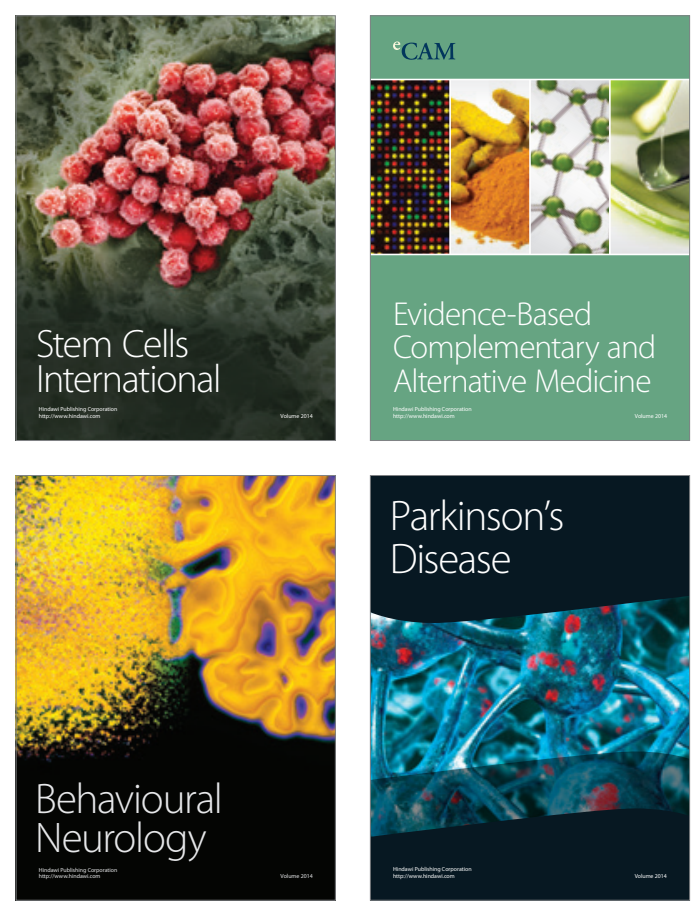

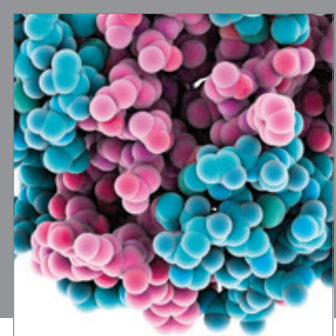

Journal of
Diabetes Research

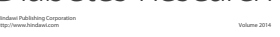

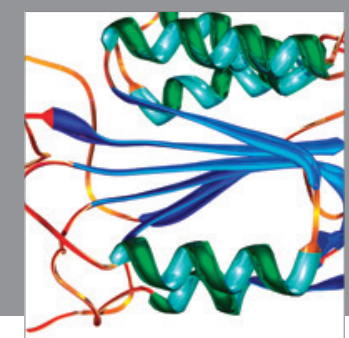

Disease Markers
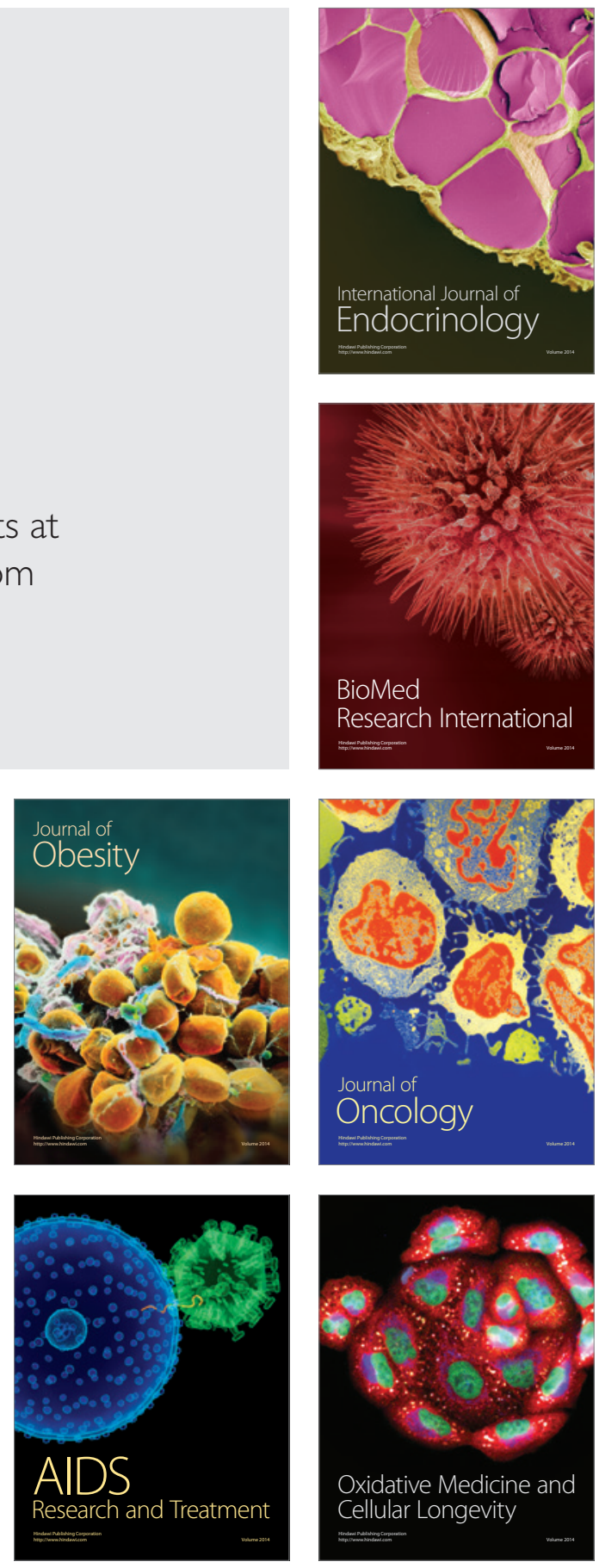